\title{
Yvette Veyret, 1999, Géo-environnement
}

Paris, SEDES.

\section{Céline Claude}

\section{(2) OpenEdition}

\section{Journals}

Édition électronique

URL : http://journals.openedition.org/rge/4261

DOI : $10.4000 /$ rge. 4261

ISSN : 2108-6478

Éditeur

Association des géographes de l'Est

Édition imprimée

Date de publication : 1 janvier 2000

ISSN : 0035-3213

Référence électronique

Céline Claude, «Yvette Veyret, 1999, Géo-environnement », Revue Géographique de l'Est [En ligne], vol. 40 / 1-2 | 2000, mis en ligne le 07 août 2013, consulté le 23 septembre 2020. URL : http:// journals.openedition.org/rge/4261 ; DOI : https://doi.org/10.4000/rge.4261

Ce document a été généré automatiquement le 23 septembre 2020.

Tous droits réservés 


\section{Yvette Veyret, 1999, Géo- environnement}

Paris, SEDES.

Céline Claude

\section{RÉFÉRENCE}

Yvette Veyret, 1999, Géo-environnement, Paris, SEDES.

1 Cette collection SEDES-Campus se caractérise par sa clarté et sa valeur pédagogique, grâce à sa composition en trois parties : analyse et synthèse, documents commentés, repères et outils, sa concision et le recours aux caractères gras pour faire ressortir les mots clefs ; grâce aussi aux résumés en début de chapitre, aux synthèses concises en fin de chapitre et à divers encadrés dans le corpus du texte, mettant en valeur des définitions, des données chiffrées....

2 Les 3 premiers chapitres: perception de la nature et de l'environnement, la longue anthropisation de la planète, géographie et environnement réfléchissent à la notion d'environnement par rapport à son contenu géographique (le titre de l'ouvrage associe les deux « disciplines »).

3 Ils permettent une mise en place du vocabulaire inhérent à une démarche géoenvironnementale: rupture, perturbation, développement durable, géosystème, aménagement, protection, gestion, patrimoine...

4 Les 6 chapitres suivants appliquent cette démarche à des espaces précis : l'espace agricole, les espaces ruraux non agricoles, les espaces protégés, les risques urbains. Ils répondent aux questions : quels aménagements, quelles gestions, quels enjeux ?, puis présentent les multiples acteurs et la législation qui s'applique à ces cas concrets.

5 Le dernier chapitre, "l'analyse globale à l'échelle du bassin versant », tente de cerner l'environnement au sein d'une unité hydrologique en intégrant les modifications naturelles et anthropiques l'affectant. 
6 Ces 7 chapitres sont alimentés d'exemples, de cas précis et récents, pris dans l'espace français.

7 Sur les 17 figures présentes dans cette partie analytique, aucune n'est nouvelle : elles sont toutes extraites d'ouvrages, d'auteurs autres que Y. VEYRET, à l'exception d'une figure.

8 Néanmoins, les choix sont judicieux et probants et le panel de documents varié.

9 Les deux dernières parties présentent des documents et des outils intéressants et divers.

\section{AUTEURS}

CÉLINE CLAUDE

Université de Nancy 2 